\title{
UMA DISCUSSÃO TEÓRICA DA RELAÇÃO DO VALOR DA MARCA E DO VALOR DO CLIENTE
}

\author{
A theoretical discussion over brand equity and \\ customer equity relationship
}

Envio 31.07.08 / Aceite 10.08.08

\author{
Bruno Bordeaux Rego ${ }^{1}$ \\ Marta Olivia Rovedder de Oliveira ${ }^{2}$ \\ Fernando Bins Luce $^{3}$
}

\section{Resumo}

Ao longo das ultimas décadas, surgiu uma nova lógica para o marketing: a lógica dominante do serviço que cada vez mais se baseia nos recursos intangíveis. O marketing tornouse uma nova missão dentro da empresa: criar e gerir os ativos baseados em mercado para entregar valor ao acionista. Apesar do valor da marca e o valor do cliente despontarem como

\footnotetext{
${ }^{1}$ Atualmente é consultor da empresa MarketData Global Consulting e mestrando do Programa de Pós-Graduação em Administração, ênfase em Marketing, da Escola de Administração da Universidade Federal do Rio Grande do Sul. Possui graduação em Administração pela Universidade de São Paulo (USP) (2005). Endereço: Rua Dr. Lauro Pimental, 695 - Cidade Universitária - Campinas, SP, CEP 13083-250. Telefone: + 551182995051 . E-mail: bruno_ bordeaux@yahoo.com.br

${ }^{2}$ Atualmente é mestranda do Programa de Pós-Graduação em Administração, ênfase em Marketing, da Escola de Administração da Universidade Federal do Rio Grande do Sul. Possui graduação em Administração pela Universidade Federal de Santa Maria (2004) e em Administração - Comércio Exterior pela Faculdade Metodista de Santa Maria (2005). Possui experiência na área de Administração, com ênfase em Marketing e Comércio Internacional. Endereço: Av. Loureiro da Silva, 1500, apto. 1312. Centro. Porto Alegre - RS. 90010460. Telefone: + 5551 3392- 8880. E-mail: moroliveira@ea.ufrgs.br

${ }^{3}$ Possui doutorado em Administração de Empresas pela Michigan State University (1982), mestrado em Master of Business Administration pela Michigan State University (1974) e graduação em Administração de Empresas pela Universidade Federal do Rio Grande do Sul (1971). Atualmente é consultor ad hoc do Conselho Nacional de Desenvolvimento Científico e Tecnológico, consultor ad hoc da Fundação de Amparo à Pesquisa do Estado do Rio Grande do Sul, professor titular da Universidade Federal do Rio Grande do Sul, consultor ad hoc da Coordenação de Aperfeiçoamento de Pessoal de Nível Superior e Membro de corpo editorial da RAC. Tem experiência na área de Administração, com ênfase em Administração de Empresas. Endereço: Sala 447 do prédio da Escola de Administração - Rua Washinton Luis, 855 - Centro - Porto Alegre, RS. CEP: 90010-460. Telefone: + 5551 3308-3148. E-mail: fbluce@ea.ufrgs.br
} 
os principais ativos nessa jornada, a relação entre os dois conceitos é ainda controversa na academia. Enquanto alguns autores entendem o valor da marca como antecedente do valor do cliente, outros pesquisadores vêem como conceitos complementares. O presente artigo fomenta uma discussão teórica, buscando compreender a relação entre o valor da marca e o valor do cliente. Para tanto, realiza uma pesquisa de cunho exploratório, através de uma revisão das principais literaturas sobre esses assuntos. Ao realizar uma comparação entre os dois ativos, percebe-se que são conceitos complementares, devendo ser administrados conjuntamente. Por fim, apresenta-se uma proposta de modelo teórico sobre a relação de ambos os construtos, sugerindo a realização de futuros estudos empíricos sobre o tema.

Palavras-chave: Valor do Cliente; Valor da Marca; Ativos Intangíveis de Marketing; Relação; Marketing Metrics.

\begin{abstract}
Last decades, a new logic for the marketing emerged: the dominant logic of services which is more and more based on intangible resources. The marketing assumed a new mission on the company: to create and to manage the market based resources to deliver value to the shareholder. Although the brand equity and customer equity emerged as the main assets on this journey, the relationship between both is still controversy in the academy. While some authors understand brand equity as an antecedent of the customer equity, other researchers see these concepts as complementary. The present article presents a discussion trying to understand the relationship between brand equity and customer equity. For that, there is an exploratory research through a revision of the main literature about these topics. When these two assets are compared, it is possible to notice that they are complementary concepts, and should be managed together. At the end, there is a proposal of a theoretical model about the relationship of the two constructs and future empirical studies about the topic are suggested.
\end{abstract} Metrics.

Keywords: Customer Equity; Brand Equity; Intangible Marketing Assets; Relation; Marketing

\title{
1 Introdução
}

Ao longo das últimas décadas surgiu uma nova lógica para o marketing: a servicedominant logic (S-D logic) ou a lógica dominante do serviço (VARGO e LUSCH, 2004), baseada na convergência de diferentes perspectivas teóricas, tais como o Marketing de Relacionamento, o Marketing de Serviços, a Orientação para Mercado, a Administração da Qualidade, a Administração de Valor e da Cadeia de Valor, a Visão Baseada em Recursos e a Análise de Redes. O enfoque dado por essa nova lógica não é mais nos recursos tangíveis, no valor inserido ou nas transações, mas sim nos recursos intangíveis como as habilidades, as informações e conhecimentos, na co-criação de valor entre a organização e no cliente e, especialmente, nos relacionamentos (VARGO e LUSCH, 2004).

Em paralelo, observa-se a perda de espaço do Marketing dentro das organizações. Os profissionais de marketing estão, em muitos casos, desacreditados dentro das empresas (SHETH e SISODIA, 1995a; SHETH e SISODIA, 1995b; RUST, LEMON e ZEITHAML, 2004; VERHOEF e LEEFSLANG, 2008). Esse movimento ocorre pela incapacidade dos gestores de marketing em justificar seus investimentos e seus respectivos efeitos no desempenho financeiro da organização e de demonstrar a sua influência sobre o valor do acionista (DOYLE, 2000). Assim, as empresas possuem grande necessidade do desenvolvimento de medidas eficazes para a solução dessa questão (SRISVATAVA, SHERVANI e FAHEY, 1998; SHETH e SISODIA, 1995a;

Rev. Adm. UFSM, Santa Maria, v. 1, n. 2, p. 275-290, mai./ago. 2008 
SHETH e SISODIA, 1995b). O estabelecimento de instrumentos adequados de mensuração é uma das questões relevantes na área de marketing (GRINBERG e LUCE, 2000; GRINBERG, 2001). Surge na academia uma linha de pesquisa dedicada à medição do desempenho das ações de marketing das empresas: o Marketing Metrics (MSI).

Com essas mudanças, seja as provocadas pela nova lógica dominante e/ou pela perda de importância dentro das organizações, o Marketing teve seu papel alterado. Segundo Srisvatava, Shervani e Fahey (1998), o novo papel do marketing é de criar e gerir os ativos baseados em mercado, tais como clientes, marcas e redes, para entregar valor aos acionistas.

Atualmente os principais ativos de mercado são as marcas e os clientes, pois comprovadamente impactam o valor da firma. O valor da marca segundo a perspectiva do cliente trata do efeito diferencial do conhecimento da marca na resposta do consumidor para as ações de marketing desta marca (KELLER, 1993, 1998, 2003). No presente estudo, no intuito de não suscitar as freqüentes confusões, será utilizado o termo valor da marca segundo a perspectiva do cliente (KELLER e LEHMANN, 2005). O valor do cliente, por sua vez, é a "soma total do valor vitalício do cliente descontado sobre todos os clientes atuais e potenciais da firma" (RUST, LEMON e ZEITHAML, 2004, p.110). Com essa nova incumbência, o marketing deve cada vez mais buscar portfólios ótimos de ativos de modo a maximizar a entrega de valor ao acionista. Para tal, se faz necessário entender a inter-relação entre os ativos baseado em mercado e as formas de gerenciamento conjunto.

Ambler et al. (2002) e Villanueva e Hanssens (2007) reconhecem a carência de estudos sobre a relação do valor da marca e do valor do cliente e propõe pesquisas adicionais que examinem de forma mais acurada as potenciais sinergias. Keller e Lehmann (2005) ao estudar marcas e o gerenciamento dessas apontam três tipos de estudos que merecem pesquisas futuras pelos acadêmicos. Primeiramente, questionam como os conceitos de valor da marca e valor do cliente podem ser integrados. Em segundo lugar, perguntam o quão próximo estão os conceitos e suas respectivas medidas. Por fim, levantam como questão de pesquisa a forma pela qual a gestão pode equilibrar o foco em orientado para marcas/produtos com o foco em clientes. Gupta e Zeithaml (2005) afirmam que os estudos relacionados ao valor do cliente e ao valor da marca praticamente cresceram de forma independente e, conseqüentemente, a inter-relação entre os dois gera confusões entre os pesquisadores.

Alguns estudos já tentaram compreender a relação entre esses dois ativos, como o de Rust et al. (2004a) que identificaram o valor da marca, juntamente com o value equity e o relationship equity como antecedentes do valor do cliente. Tal linha de pensamento é exemplificada na afirmação dos autores de que marcas vão e vem - mas clientes ... se mantêm". No entanto, Leone et al. (2006) questionam tal premissa e afirmam que o valor da marca e o valor do cliente são conceitos complementares. Seu argumento pode ser resumido na seguinte frase que contrapõe a afirmação de Rust et al. (2004a): "através dos anos, clientes podem ir e vir, porém marcas fortes irão perdurar". Essas visões conflitantes demonstram que não há consenso na academia quanto à relação entre os dois construtos. Assim, o presente estudo busca responder o seguinte questionamento: Qual é a relação entre Valor da Marca e Valor do Cliente?

Para buscar possíveis soluções a esse questionamento, este estudo trata-se de um ensaio teórico, baseado em uma pesquisa qualitativa, uma vez que essa "proporciona melhor visão e compreensão do contexto do problema" (MALHOTRA, 2001, p. 155). Esse trabalho possui caráter exploratório, apresentando uma vasta revisão da literatura internacional sobre esses assuntos, uma vez que o objeto de estudo é pouco explorado no contexto brasileiro. Em recente levantamento sobre publicações que tratam do valor da marca no cenário nacional, 
ou seja, apenas um dos construtos abordados no presente estudo, Oliveira (2008) apontou que, devido à importância do tema e à incipiência da pesquisa no Brasil, percebe-se que ainda há um bom espaço para o aprofundamento dos conhecimentos necessários tanto para os acadêmicos quanto para os práticos.

A presente pesquisa apresenta primeiramente uma revisão bibliográfica sobre os conceitos mais relevantes do marketing metrics, para, em seguida, introduzir uma revisão teórica sobre os principais conceitos do valor da marca - discorrendo sobre as principais definições e dimensões -, bem como sobre o valor do cliente, realizando também um levantamento dos seus principais antecedentes. Na seqüência, é promovida uma discussão teórica sobre como os dois conceitos - o valor da marca e valor do cliente - podem estar interligados. Por fim, são propostos um modelo teórico sobre a relação entre os dois construtos analisados e sugestões de futuras pesquisas sobre o tema.

\section{Marketing metrics}

A mensuração do efeito do desempenho do marketing nas empresas tem sido intensificada, enquanto as empresas sentem aumentar a pressão para justificar os gastos em marketing (SRIVASTAVA, SHERVANI e FAHEY; 1998; RUST et al., 2004b; GUPTA e ZEITHAML, 2005). A "maior parte da perspectiva acadêmica sobre esse assunto foca-se em torno do marketing financeiramente contável ou em uma ponte sobre o gap entre as disciplinas de marketing e finanças" (BAKER e HOLT, 2004, p. 558). Rust et al. (2004b) propõem uma cadeia da produtividade de marketing, conforme mostra a Figura 1, que busca demonstrar o necessário vínculo entre essas áreas.

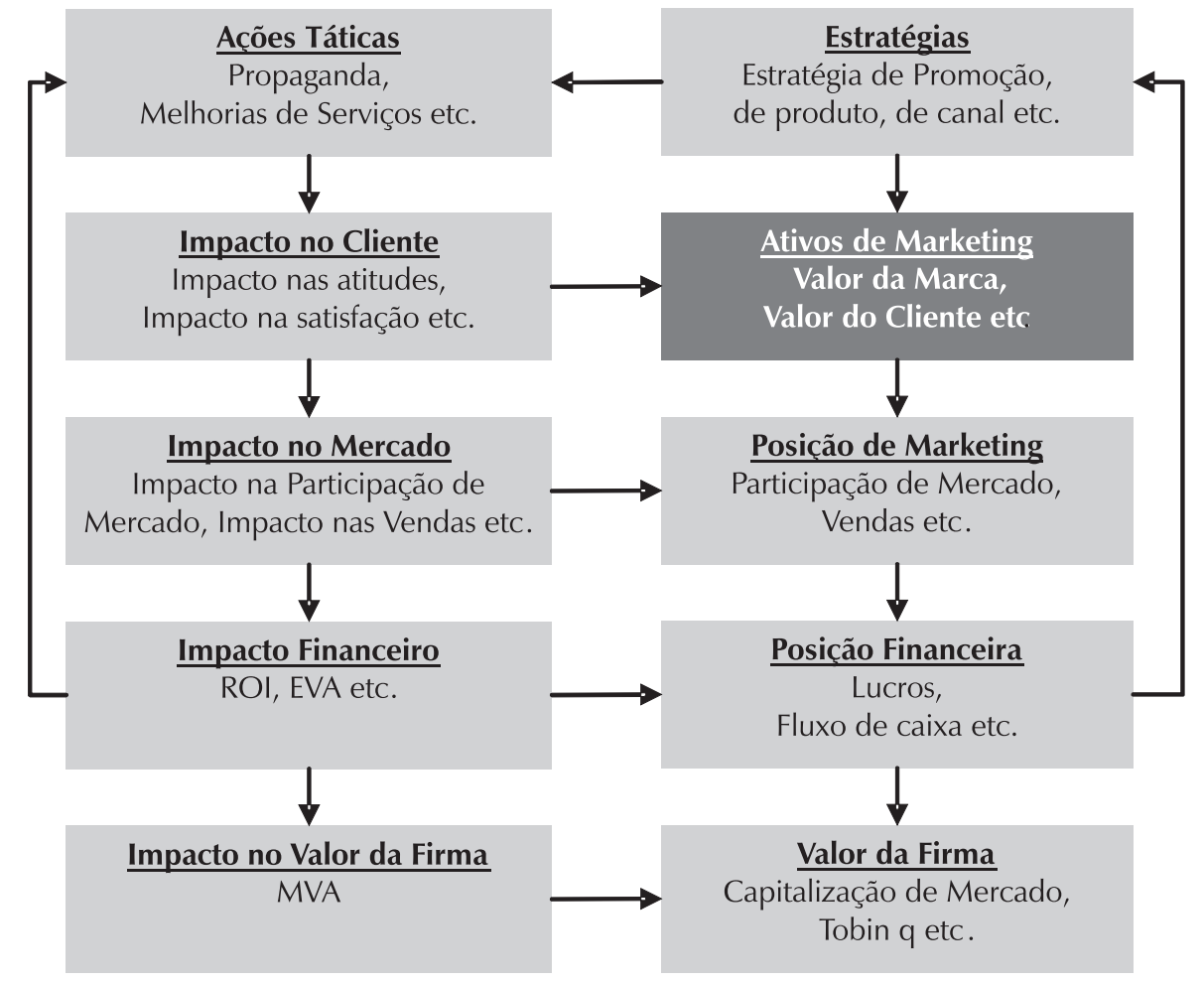

Fonte: Rust et al. (2004b, p. 77).

Figura 1 - Cadeia de Produtividade do Marketing 
Essa cadeia demonstra como ocorre a interligação entre finanças e marketing. Toda e qualquer ação de marketing possui um impacto financeiro na organização, sendo o valor da firma o objetivo fim. Isso consolida o papel-chave do acionista frente aos demais stakeholders da organização. Merece destaque no esquema a importância dos ativos de marketing, em especial o valor da marca e o valor do cliente. Cada vez mais os profissionais de marketing devem entender a relação entre esses, de forma a gerenciá-los conjuntamente. Uma gestão isolada de cada um desses ativos pode resultar em desperdício de recursos e, conseqüentemente, em uma entrega de valor inferior ao esperado pelo acionista.

\section{Valor da marca}

Nos últimos 15 anos, é inegável a importância do valor da marca para diferentes áreas do conhecimento (RAGGIO e LEONE, 2007), tais como o marketing, estratégia, economia, finanças e contabilidade. Estrategicamente, marcas fortes representam um componente da vantagem competitiva e fonte de futuros ganhos da empresa (BALDAUF, CRAVENS e BINDER, 2003). Dentro da área de marketing, o valor da marca ganhou crescente atenção, sendo tópico prioritário para acadêmicos e práticos.

Embora o valor da marca tenha sido muito estudado na literatura, inexiste um consenso das definições e métricas (VILLANUEVA e HANSSENS, 2007). Um dos motivos dessas divergências é as diferentes perspectivas nas quais a marca pode ser analisada, devido a diferentes propósitos de apresentação de seu valor (KELLER, 1998). Segundo Keller e Lehmann (2005, p. 13), existem três perspectivas principais e distintas no estudo do valor da marca: baseada no cliente, baseada na empresa e a financeira. O valor da marca segundo o ponto de vista do cliente é a parte da "atração ou repulsão de um produto particular de uma empresa particular gerado pela parte 'não objetiva' da oferta do produto e não pelos atributos do produto per se". Já o valor da marca segundo a perspectiva da empresa é o valor adicional acumulado pela empresa ao longo do tempo (ex. fluxo de caixa) por causa da presença do nome da marca e que não existiria caso o produto não possuísse marca. Por fim, a perspectiva financeira considera "o valor da marca como o preço que a marca traz ou pode trazer no mercado financeiro" (KELLER e LEHMANN, 2005, p.16).

O presente estudo foca-se no valor da marca segundo a perspectiva do cliente, observando esse construto segundo uma perspectiva mais estratégica. Para o AMA (2008), "da perspectiva do cliente, valor da marca é baseado nas atitudes do consumidor sobre atributos positivos da marca e conseqüências favoráveis do uso da marca". Assim, destacam-se quatro vertentes: Srivastava e Shocker (1991), Keller (1993, 1998, 2003), Aaker (1998) e Yoo e Donthu (2001).

Srivastava e Shocker (1991) identificam que o valor da marca é um construto complexo e composto por seis dimensões: os construtos perceptuais (ex. qualidade percebida, risco, conjunto evocado, busca de informação); os comportamentos de mercado (ex. lealdade à marca, troca, disposição para pagar preço premium, taxas de uso); as estratégias de marketing (ex. extensões de marca, licenciamento, novos mercados); as condições da indústria (ex. intensidade competitiva, estágio do ciclo de vida do produto); as mensurações de desempenho (preço, participação de mercado, vulnerabilidade); e a avaliação financeira (ex. valor do consumidor, dadas taxas de uso, preço premium, taxas de retenção individuais e por segmento, lucratividade e risco por segmento e por mercado).

Keller $(1993,1998,2003)$ define valor da marca baseada no consumidor como "o efeito diferencial do conhecimento da marca na resposta do consumidor para as ações de 
marketing desta marca". O conhecimento da marca, conceito principal da definição, segundo Keller (1993, 1998, 2003), é definido por dois componentes:

- lembrança da marca que está relacionada com a habilidade do cliente recordar ou reconhecer a marca em condições diferentes de acordo com a força da marca em sua memória;

- imagem da marca que é definida como as percepções e preferências do cliente junto a uma marca a partir de vários tipos de associações da marca contidas na memória do cliente.

Aaker (1996, p. 7-8) considera o valor da marca como "um conjunto de ativos (e passivos) ligados ao nome de uma marca que se somam (ou se subtraem) do valor proporcionado por um produto ou serviço para uma empresa e/ou para os consumidores". Segundo Aaker (1998), os ativos e passivos que compõem o valor da podem ser agrupados em cinco classificações (ver Figura 2):

- lealdade à marca: trata-se do "ativo-chave" de valor da marca sendo concomitantemente antecedente e conseqüente do construto;

- qualidade percebida: é definida como o conhecimento que o consumidor tem da qualidade geral ou da superioridade de um produto ou serviço pretendido em relação a alternativas conhecidas por ele no mercado;

- lembrança do nome (da marca): é a capacidade que um comprador em potencial tem de reconhecer ou de se recordar de uma marca como integrante de certa categoria de produtos;

- associação de marca: é uma imagem na memória conectada com uma marca. A imagem pode ser um conjunto de associações usualmente organizadas de forma significativa para o consumidor. Deve-se salientar que, elas representam percepções do consumidor, podendo ou não refletir a realidade objetiva;

- outros ativos: referem-se a ativos da empresa, como patentes, marcas registradas e as relações com os canais de distribuição.

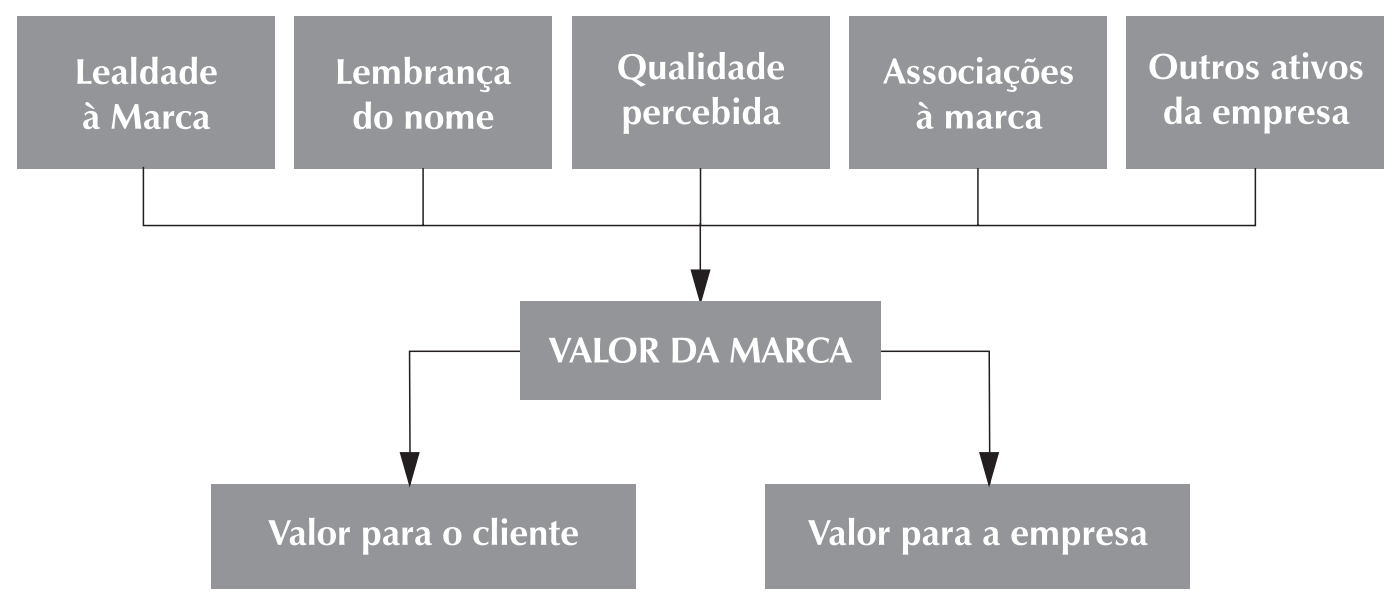

Fonte: Adaptado de Aaker (1998).

Figura 2 - Arcabouço de Aaker de "valor da marca".

Recentemente, Yoo e Donthu (2001) desenvolveram e validaram um instrumento de mensuração do valor da marca na Coréia do Sul e nos EUA. Posteriormente, Neto (2003) validou o instrumento no contexto brasileiro. Essa escala combinou os conceitos de Aaker (1998) e Keller (1993), validando apenas três dimensões do valor da marca: a lealdade à marca, a qualidade percebida e as lembranças/associações da marca. A grande contribuição dos estudos 
foi a reunião da lembrança de marca e das associações da marca em uma única dimensão de valor da marca.

\section{Valor do cliente}

O valor do cliente é uma linha de pesquisa recente dentro de marketing. A origem do valor do cliente pode ser compreendida a partir de algumas linhas de pesquisa sobrepostas: o marketing direto, a qualidade em serviços, o marketing de relacionamento e o valor da marca (HOGAN, Lemon e Rust, 2002). Trata-se de uma área pouco estudada na literatura de marketing (VILLANUEVA e HANSSENS, 2007) e que vem ganhando espaço com o aumento da participação dos serviços na economia.

O estudo do valor do cliente apresenta dois objetivos bem definidos: a mensuração econômica dos relacionamentos dos clientes e a identificação de estratégias que construam relacionamentos lucrativos (VILLANUEVA e HANSSENS, 2007). Embora o conceito possa ser calculado de diversas formas, sua definição consensual é "soma total do valor vitalício do cliente descontado sobre todos os clientes atuais e potenciais da firma" (RUST, LEMON e ZEITHAML, 2004). O customer lifetime value (CLV), base do valor do cliente, é afetado por considerações de receita e custos relacionadas aos três elementos: aquisição, retenção e expansão de clientes (GUPTA et al., 2006; BERGER et al., 2002).

Blattberg e Deighton (1996) definiram, em seu trabalho seminal, o valor do cliente em termos do equilíbrio ótimo entre o que foi gasto na aquisição de clientes versus o que foi gasto na retenção. Assim, oferecem oito direcionamentos para a maximização do valor do cliente: (1) investir nos clientes lucrativos em primeiro lugar; (2) transformar a administração de produtos em administração de clientes; (3) considerar como incremento de vendas e que o cross-selling pode incrementar o valor do cliente; (4) buscar formas de reduzir os custos de aquisição; (5) acompanhar os ganhos e as perdas de valor do cliente frente aos programas de marketing; (6) relacionar o branding ao valor do cliente; (7) monitorar o poder de retenção de seus clientes; (8) considerar a elaboração de dois planos de marketing ou até mesmo a formação de duas organizações separadas voltadas aos esforços de aquisição e retenção.

Rust, Lemon e Zeithaml (2004) pautam-se pelo conceito da centralidade do cliente, ou seja, o marketing deve subordinar suas ações em busca da maximização do valor do cliente. Para os autores, o valor do cliente possui três condutores principais, conforme apresenta a Figura 3.

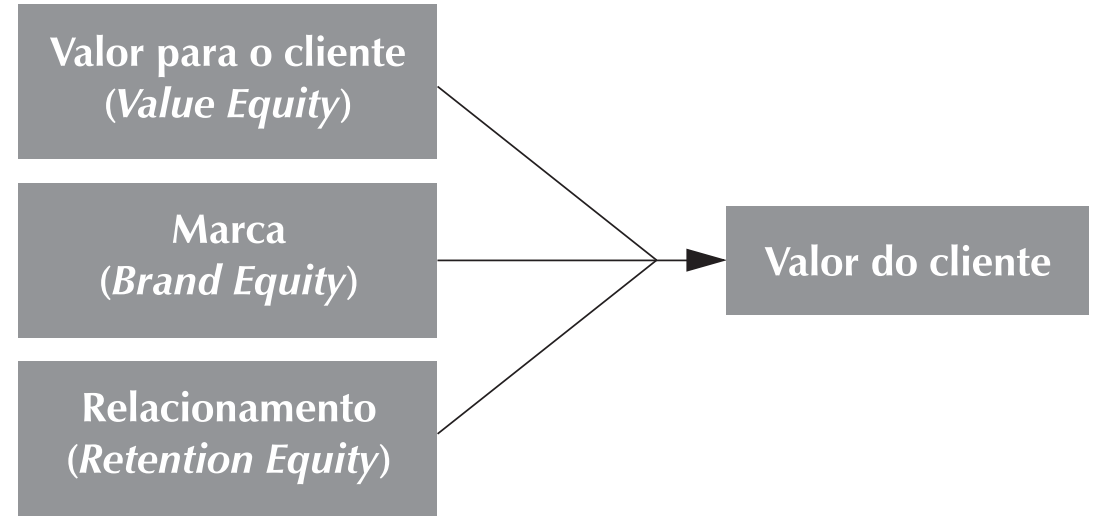

Fonte: Rust, Lemon e Zeithaml (2004).

Figura 3 - Relações entre o valor da marca e o valor do cliente. 
O valor para o cliente (value equity) é "a avaliação objetiva feita pelo cliente, da utilidade de uma marca, com base em percepções daquilo que é dado em troca do que é recebido" (RUST et al., 2000, p. 68). São três os condutores do value equity: o preço, a qualidade e a conveniência. Já o valor da marca (brand equity) pode ser definido como "a avaliação subjetiva e intangível da marca pelo cliente, além e acima do valor percebido de forma objetiva" (RUST et al., 2000, p. 81). Os autores elencam três condutores-chave: a lembrança da marca, as atitudes do cliente frente à marca e as percepções éticas da marca por parte do cliente. Por fim, o Relacionamento ou Relationship equity trata da "tendência do cliente permanecer com a marca, além e acima de suas avaliações objetiva e subjetiva da mesma" (RUST et al., 2000, p. 85). São quatro condutores principais: os programas de lealdade, os programas de tratamento e reconhecimento especial, os programas de construção de comunidades e os programas de construção de conhecimento. Este arcabouço teórico foi validado no contexto brasileiro em 2007, com uma replicação no mercado de telefonia celular (KEISERMAN, 2007).

O conceito de valor do cliente está intimamente ligado a CRM. Assim, Kumar (2006) enuncia os seguintes direcionamentos para uma estratégia de CRM eficiente: (a) conhecer os seus clientes o suficiente para entregar valor superior, maximizando a rentabilidade da empresa; (b) adotar uma métrica que antecipe o CLV para tomadas de decisões superiores e estratégias de gerenciamento de clientes que se voltem a maximização do CLV; (c) selecionar os clientes que possuem CLV alto e médio, para abordá-los futuramente; (d) alocar o orçamento de marketing ótimo ao longo de diferentes bases de clientes/distribuidores baseados em sua receita "futura" potencial; (e) vender o produto certo para o cliente certo no tempo certo; $(\mathrm{f})$ balancear os recursos voltados à retenção e aquisição, focando o gasto ótimo; (g) minimizar a saída dos clientes/distribuidores de alto valor; (h) encorajar os clientes de canais únicos a se tornarem clientes de múltiplos canais.

\section{Relação entre o valor da marca e valor do cliente: proposições}

A relação entre valor da marca e valor do cliente é controversa entre os acadêmicos. Rust, Lemon e Zeithaml (2004) entendem que o valor da marca é um antecedente do valor do cliente. Os autores adotam uma definição estreita do valor da marca, considerando apenas os aspectos subjetivos inerentes à marca, sendo que os aspectos objetivos da marca estão contidos no outro antecedente, o value equity. Essa visão da relação entre os dois ativos suporta que as ações de branding devam estar direcionadas a aumentar o valor do cliente. Ou seja, o valor da marca estaria subordinado ao valor do cliente, conforme mostra a Figura 4.

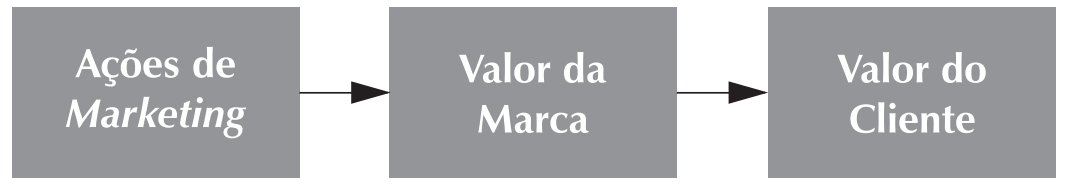

Fonte: Autores.

Figura 4 - O valor da marca como antecedente do valor do cliente.

Assim, enuncia-se a seguinte proposição teórica:

P1a: O valor da marca é um antecedente do valor do cliente. 
Em contrapartida, Leone et al. (2006) discordam de tal posicionamento, argumentando que essa perspectiva talvez minimize o desafio e o valor de marcas fortes, enfatizando excessivamente o valor do cliente. Para Leone et al. (2006), valor da marca e valor do cliente são noções complementares, conforme mostra a Figura 5.

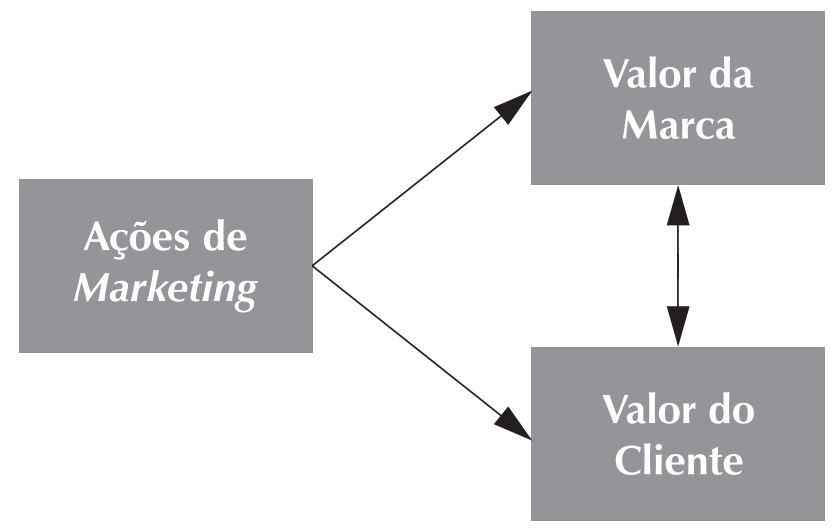

Fonte: Autores

Figura 5 - O valor da marca como antecedente e conseqüente do valor do cliente.

Enquanto o valor da marca enfatiza mais o "front end" dos programas de marketing e o valor intangível - criado potencialmente pelos programas de marketing -, o valor do cliente foca-se mais no "back end" dos programas de marketing, preocupando-se com o valor das atividades de marketing em termos de receitas. Os autores criticam a centralidade do cliente, pois crêem que isso ignora algumas vantagens importantes que se pode obter com marcas fortes. São exemplos disso: a atração de funcionários de alta qualidade, o estímulo a um suporte mais forte dos parceiros de canal e da cadeia de suprimentos, a criação de oportunidades de crescimento através de extensões de linha e categoria e o licenciamento (LEONE et al., 2006). Portanto, a partir desta abordagem deriva-se outra proposição teórica, P1b, sendo essa concorrente a P1a:

\section{cliente.}

P1b: O valor da marca é ao mesmo tempo antecedente e conseqüente do valor do

Leone et al. (2006) explicam a complementaridade dos dois ativos de marketing por meio do modelo preliminar demonstrado na Figura 6. Conforme apontado por esse autores, o valor da marca é composto por cinco componentes principais: as associações da marca, a atitude da marca, as preferências e a lealdade à marca, as escolhas da marca e outros como serviços. O valor do cliente, por sua vez, possui quatro componentes: a aquisição, a retenção, o crossselling e outros tais como os serviços de pós-compra entre outros. Além disso, os pesquisadores incorporam variáveis internas da empresa, como suas atividades de marketing realizadas para gerenciar os ativos de marketing. Ademais, as variáveis externas também são incorporadas ao modelo, como o ambiente no qual a empresa atua e a competição das atividades de marketing realizadas por outras empresas no mercado. 


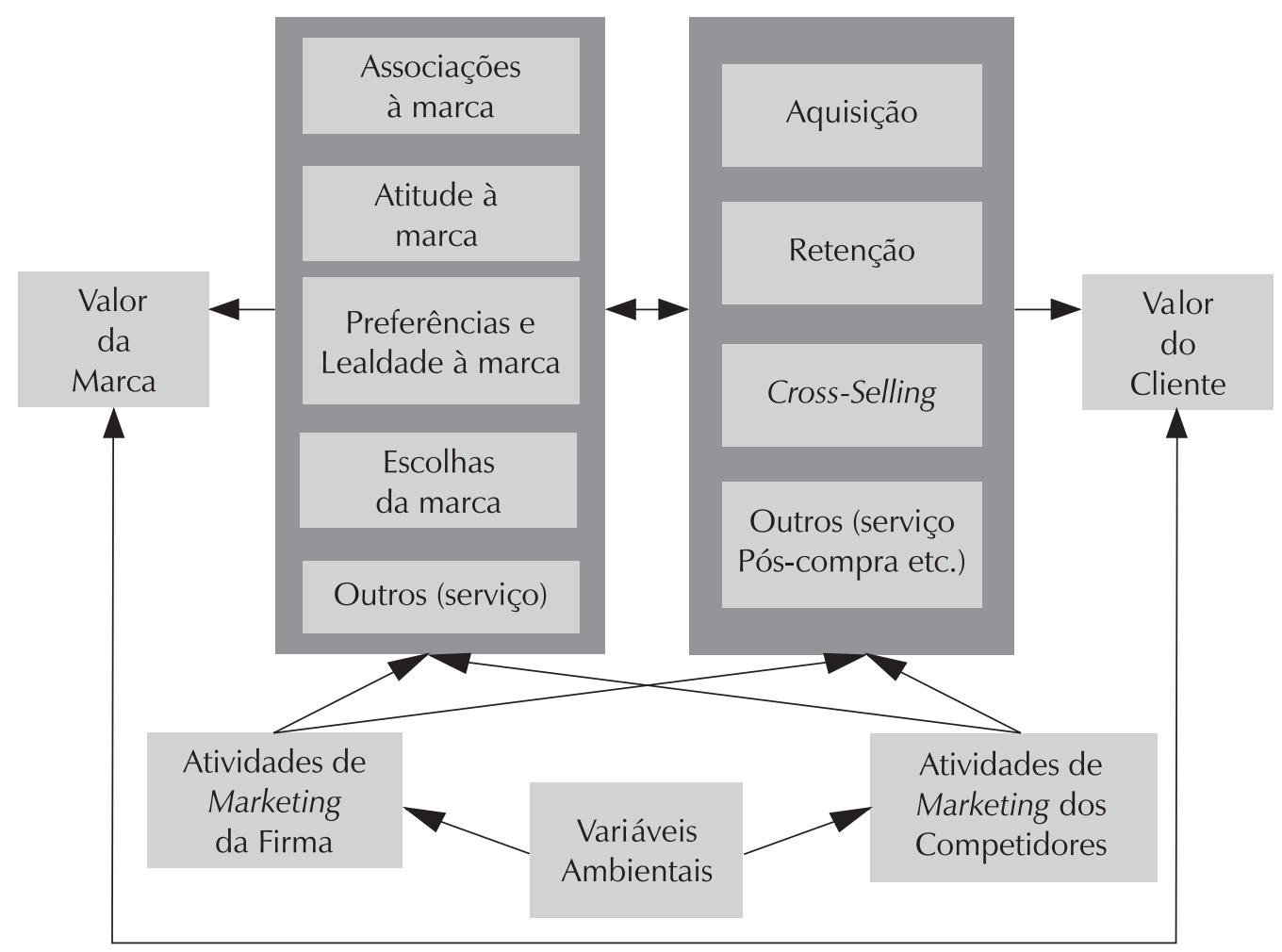

Fonte: Leone et al. (2006).

Figura 6 - Modelo preliminar para relacionar o valor da marca com o valor do cliente.

Para compreender melhor qual das duas proposições está mais adequada à realidade, faz-se necessária uma comparação entre o valor da marca e o valor do cliente, verificando qual das proposições teóricas é mais adequada.

\section{Discussão}

Ao analisar os construtos, alguns teóricos apontam que ambos são ativos intangíveis (SRISVATAVA, SHERVANI e FAHEY, 1998) de horizonte de longo prazo e baseiam-se fundamentalmente no construto da lealdade (VILLANUEVA e HANSSENS, 2007).

A similaridade apresentada pelos autores quanto à lealdade é refutada quando se analisa mais apuradamente esse construto, principalmente pela perspectiva da lealdade dinâmica, ou seja, a lealdade se desenvolve ao longo do tempo através de uma seqüência de quatro fases (OLIVER, 1999). De início, o cliente é cognitivamente leal, a seguir passa a ser afetivamente leal, depois, conativamente leal, por fim, torna-se ativamente leal. Nota-se que cada ativo atua em uma etapa diferente. O valor da marca está mais presente na lealdade cognitiva, fase baseada somente na crença construída com as informações disponíveis acerca de atributos de desempenho e na lealdade afetiva, que é marcada por uma atitude positiva para com a marca, resultante de sucessivas experiências satisfatórias. Por outro lado, o valor do cliente atua mais na fase final, a lealdade de ação, quando as intenções de compra são convertidas em uma ação, a compra propriamente dita.

Para Villanueva e Hanssens (2007), as linhas de pesquisa do valor da marca e do valor do cliente são significantemente diferentes em vários aspectos: 
- definição: enquanto a definição de valor do cliente é praticamente padrão dentro da literatura, existem diversos modelos que mensuram o valor da marca, muitos deles desenvolvidos pelos praticantes;

- unidade de análise: enquanto o valor da marca se pauta, muitas vezes, por uma visão por produto, o valor do cliente é centrado na perspectiva do cliente;

- nível de análise: enquanto o valor da marca usualmente mensura as atitudes dos clientes, o valor do cliente mensura comportamento observáveis;

- metodologias: os modelos que valoram as marcas são, em sua maioria, descritivos; já os modelos de valor do cliente tendem a ser analíticos e estatísticos;

- métricas: cada ativo possui uma forma pela qual é impactado pelo marketing e, conseqüentemente, a forma como se reflete no desempenho financeiro;

- condutores e subcondutores: os condutores do valor do cliente são facilmente identificados e observados, enquanto as definições do valor da marca são mais complexas e formuladas a partir da psicologia do consumidor;

- tipos de relacionamentos e indústrias: em algumas indústrias o valor do cliente é difícil de implementar ou pode não ser relevante.

Para aprofundar o entendimento da relação entre os dois ativos, é crucial entender a forma como cada ativo agrega valor à firma (AMBLER et al., 2002). Assim, existem seis formas diferentes de incrementar o valor da organização: a extensão em novas áreas com novos clientes, a aquisição de novos clientes para as ofertas atuais, o cross-buying de novos produtos/ serviços para os clientes atuais, a habilidade de cobrar preços premium, a redução dos custos de marketing e o aumento das compras das ofertas atuais pelos clientes atuais.

A marca, em particular, possibilita à empresa expandir sua atuação por meio de novos produtos junto a novos clientes (AAKER, 1998). Ambler et al. (2002) citam o exemplo da Nike. Essa empresa entrou com sucesso no mercado de produtos ligados ao golfe. A partir de sua longa tradição em esportes, como o basquete, a corrida e o futebol, a força da marca Nike permitiu um lançamento bem-sucedido pela extensão da marca para produtos de golfe. A capacidade de extensão da marca pode ser explicada por diversos fatores, tais como: a lembrança do cliente e as associações positivas sobre a marca principal; a similaridade ou "encaixe" junto à marca principal; a qualidade comprovada e a capacidade da marca principal; e, por fim, a grande força de mercado da marca principal (AAKER, 1998).

Segundo Ambler et al. (2002), a marca como ativo permite que a empresa conquiste novos clientes utilizando-se de seu portfólio de produtos e serviços atuais. A firma pode utilizar a força da marca em seu marketing mix para trazer novos clientes. Ações de marketing de comunicação (ex. propaganda e promoções) e de distribuição (ex. habilidade em manter e aumentar espaço nas gôndolas, penetração de distribuição e relacionamento com as contas chave nacionais) encorajam novos clientes a experimentar marcas existentes. Já o cliente como ativo pode levar à aquisição de novos clientes, contudo a forma como isso acontece é diferente. Em vez de uma aquisição por estratégias de marketing, essa ocorre via "boca a boca" positiva gerada pelos clientes atuais.

O cross-buying ou cros-selling é promovido pela marca por meio de sua força, que, por causa do sucesso, muitas vezes, encoraja os clientes a comprarem produtos adicionais (AMBLER et al., 2002). Um exemplo desse fenômeno é observado pela atuação das empresas de telecomunicações no Brasil. Empresas de telefonia fixa convencem os seus atuais clientes a comprar outros tipos de produto, como, por exemplo, linhas de telefone celular, acesso banda larga a Internet e/ou pacotes de ligações de longa distância. É difícil, nesses tipos de situações, distinguir até que ponto foi influência do ativo marca ou do ativo cliente (AMBLER et al., 2002).

Rev. Adm. UFSM, Santa Maria, v. 1, n. 2, p. 275-290, mai./ago. 2008 
Aparentemente, nesse caso, os ativos atuam conjuntamente. Segundo Ambler et al. (2002), a lembrança da marca e as associações positivas a ela vinculadas influenciam o engajamento ou não na intenção de cross-buying (BRANSON, 1998 apud AMBLER et al., 2002). No que se refere ao ativo cliente, o relacionamento e o histórico do cliente com a empresa influenciam a decisão de cross-buying. Por fim, o cross-buying pode ser resultado da habilidade da empresa em disponibilizar a oferta certa no momento certo a partir do conhecimento do cliente acumulado com o tempo (KUMAR, LEMON e PARASURAMAN, 2006; KUMAR, 2008).

Tanto o ativo de clientes quanto o ativo de marcas permitem a cobrança de preços premium frente à concorrência (AAKER, 1998). Uma marca forte reduz o risco associado à compra. De forma similar, clientes que são leais a uma marca ou firma particular estão dispostos a pagar um preço mais alto (AMBLER et al., 2002). Por outro lado, as firmas ao criar relacionamentos fortes com seus clientes ao longo do tempo possibilitam o conhecimento das preferências e dos comportamentos de compra. Conseqüentemente, as empresas conseguem customizar suas ofertas, tornando-as mais valiosas e permitindo preços mais elevados que seus competidores (AMBLER et al., 2002).

A redução dos custos de marketing é outro benefício gerado tanto pelo ativo de marca quanto pelo ativo de cliente. A força das marcas reduz os custos de duas formas: por meio da extensão de marcas (KELLER, 1998) e pela necessidade menor de investimentos de manutenção da marca. O cliente como ativo reduz o custo de forma diferente. Ao mensurar a rentabilidade por cliente, a empresa consegue reduzir a quantidade de clientes que dão prejuízo e servir os clientes atuais de uma forma mais racional. Outra forma é através de relacionamentos fortes que podem viabilizar reposições de produtos automáticas por parte dos clientes, reduzindo ou até mesmo eliminando os custos de marketing (AMBLER et al., 2002).

Outra diferença entre os dois ativos refere-se à habilidade da empresa em ganhar receitas crescentes advindas dos produtos atuais pelos clientes atuais. Especificamente, a firma consegue influenciar a freqüência e a quantidade de compra do cliente. Isso ocorre pela compreensão das preferências do cliente ao longo do tempo e pela utilização de elementos do mix de promoção (ex. comunicações e força de vendas) (KUMAR, 2008).

A partir da análise das formas como cada ativo agrega valor à organização, deduz-se que o valor da marca e o valor do cliente são construtos distintos e, principalmente, complementares, respaldando a proposição 1b. Embora ambos ativos agreguem valor nas mesmas situações, essa ocorre de forma diferente. Um exemplo é a cobrança de preço premium. Enquanto a marca reduz o risco de compra, permitindo a cobrança de preços maiores, o valor do cliente possibilita que preços altos sejam cobrados devido ao maior conhecimento sobre cliente e a conseqüente customização das ofertas. Adicionalmente, existem peculiaridades de cada ativo. Enquanto apenas a marca permite a extensão em novas áreas com novos clientes, o ativo cliente é o único que possibilita o aumento das compras das ofertas atuais pelos clientes atuais.

\section{Proposta de modelo teórico}

Embasando-se nessa discussão, propõe-se uma adaptação do modelo de Leone et al. (2006), conforme ilustrado na Figura 7, seguindo a linha da proposição 1b. Basicamente o modelo busca a compreensão da relação entre os ativos. Este modelo contém as dimensões do valor da marca propostas por Aaker (1998) e validadas por Neto (2003) no contexto brasileiro (lealdade à marca, qualidade percebida e lembrança/associações da marca), e as dimensões de valor do cliente (aquisição, retenção e cross-selling) propostas por Villanueva e Hanssens (2007). 


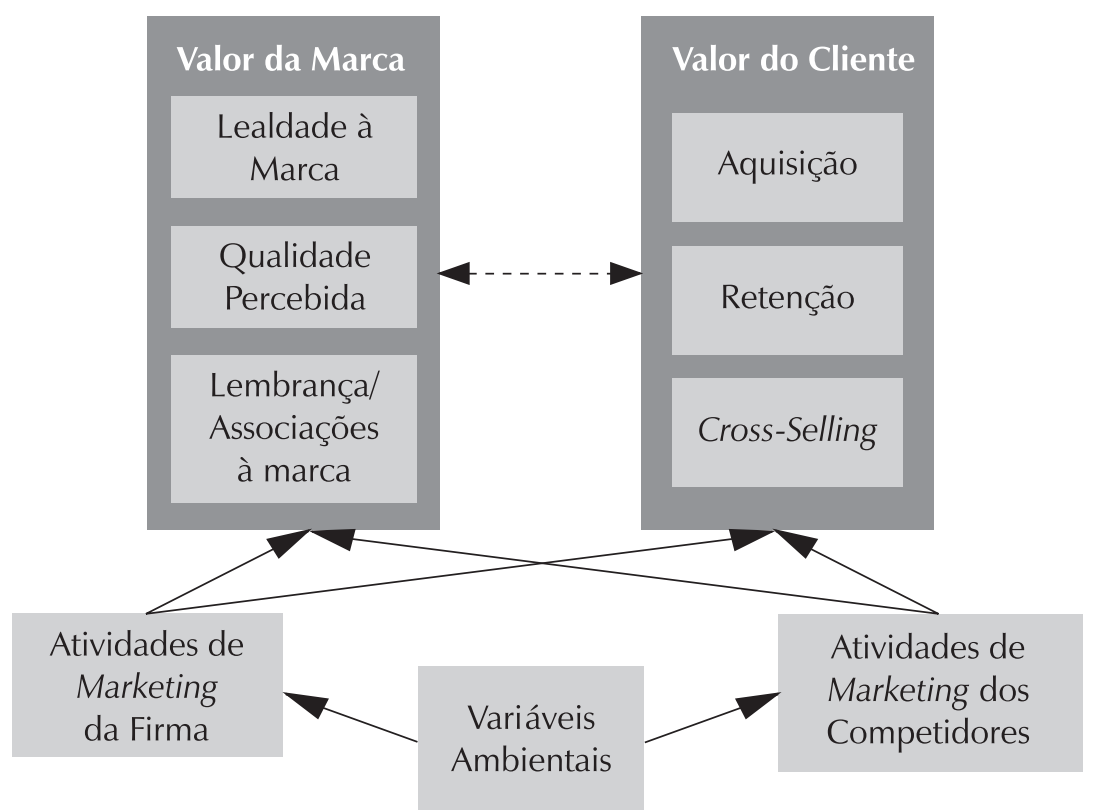

Fonte: Adaptado Leone et al. (2006).

Figura 7 - Modelo teórico - valor da marca versus valor do cliente.

Além disso, três elementos são incluídos na análise: as ações de marketing da firma, as ações de marketing dos competidores e as variáveis ambientais. A linha tracejada representa a incógnita que se busca compreender com um futuro teste empírico.

\section{Considerações finais}

O presente estudo buscou melhor compreender a relação entre os ativos de mercado, mais especificamente valor da marca e valor do cliente. Como contribuição teórica, conclui-se que o valor da marca e o valor do cliente são ativos que possuem muitas semelhanças, mas são distintos. Com base na análise dos benefícios gerados por cada um, deduz-se que valor da marca e o valor do cliente são complementares, como sugeriu Leone et al. (2006), refutando inicialmente a idéia de subordinação do valor da marca ao valor do cliente enunciada por Rust, Lemon e Zeithmal (2004). Embora ambos os ativos apresentem alguns benefícios similares como, por exemplo, o cross-buying de novos produtos/serviços para os clientes atuais, essa se dá de forma diferente. Adicionalmente, existem peculiaridades de cada ativo. A marca permite a extensão dos negócios em novas áreas com novos clientes, sendo o ativo cliente o único que possibilita o aumento das compras das ofertas atuais pelos clientes atuais.

Como contribuição prática, o presente estudo incrementou as discussões quanto à cadeia de produtividade de marketing, mais especificamente as formas de otimização e de gerenciamento conjunto do valor da marca e do valor do cliente na organização.

As limitações do estudo referem-se ao fato de a revisão teórica ter se concentrado nas principais teorias de cada construto, valor da marca e valor do cliente, e não em todas as teorias disponíveis a respeito. O valor da marca, por exemplo, foi analisado apenas sob a perspectiva do cliente, descartando-se a perspectiva da firma e a financeira.

Destaca-se que este estudo é eminentemente teórico, com o objetivo de fomentar trabalhos atinentes ao tema, não possibilitando a apresentação de respostas definitivas ao 
problema de estudo, mas sim propostas iniciais que incitem futuras pesquisas. Sugere-se, portanto, o teste empírico do modelo teórico apresentado na Figura 7. Ademais, encorajamse pesquisas que analisem as outras etapas da cadeia de produtividade de marketing que influenciem a relação entre os ativos baseados em mercado sob responsabilidade da área de marketing das organizações.

\section{Referências}

AAKER, D.A. Building Strong Brands. New York: Free Press, 1996.

AAKER, D.A. Marcas: brand equity gerenciando o valor da marca. 2. ed. São Paulo: Negócio, 1998.

AMA. American marketing association's dictionary. Disponível em: < http://www. marketing power.com./mg-dictionary $>$ Acesso em: 22 jan. 2008.

AMBLER, T. et al. Relating brand and customer perspectives on marketing management. Journal of Service Research, v. 5, n.1, p. 13-25, 2002.

BALDAUF, A.; CRAVENS, K. S.; BINDER, G. Performance consequences of brand value management: evidence from orgazations in the value chain. Journal of Product $\&$ Brand Manangement, v.12, n.4, p.220-236, 2003.

BAKER, S.; HOLT, S. Making marketers accountable: a failure of marketing education? Marketing Intelligence \& Planning, v. 22, n.5, p.557-567, 2004.

BERGER, P.D. et al. Marketing actions and the value of customer assets: A framework for customer asset management. Journal of Service Research, v.5, n.1, p. 39-54, 2002.

BLATTBERG, R. C.; DEIGHTON, J. Manage marketing by the customer equity test. Harvard Business Review, v.74, n.4, p. 136-144, 1996.

DOYLE, P. Valuing marketing's contribution.

European Management Journal, v. 18, n. 3, p. 233-245, 2000.

GUPTA, S. et al. Modeling Customer Lifetime Value. Journal of Service Research, v.9, n. 2, p. 139-155, 2006.
GUPTA, S.; ZEITHAML, V. Customer metrics: the past, the present, and the future in academia and practice. Marketing Science Institute, Special Report, n. 05-200, p. 39-75, 2005.

GRINBERG, C. S. Marketing metrics: um estudo exploratório sobre a construção do conhecimento de um novo tema em marketing. 2001. 125f. Dissertação (Mestrado em Administração - ênfase em Marketing) Programa de Pós-Graduação em Administração - Universidade Federal do Rio Grande do Sul, Porto Alegre, 2001.

GRINBERG, C. S.; LUCE, F. B. Marketing metrics: um novo desafio para a disciplina de marketing. In: ENANPAD, 24., 2000, Rio Janeiro. Anais... Rio de Janeiro: ANPAD, 2000, CD-ROM.

HOGAN, J. E.; LEMON, K.N.; RUST, R.T.

Customer equity management: charting for new directions for the future of marketing. Journal of Service Research, v. 5, n. 4, p. 4-12, 2002.

KEISERMAN, B. O customer equity na indústria de telefonia celular: uma replicação do modelo de Rust et al. (2004) no contexto brasileiro. 2007. 155f. Dissertação (Mestrado em Administração - ênfase em Marketing) Programa de Pós-Graduação em Administração - Universidade Federal do Rio Grande do Sul, Porto Alegre, 2007.

KELLER, K. L.; LEHMANN, D. R. Brands and branding: research findings and future. Priorities PAPER, 2005.

KELLER, K. L. Strategic brand management. $2^{\text {nd }}$ ed. Upper Saddle River, NJ: Prentice Hall, 2003. 
KELLER, K. L. Conceptualizing, measuring, and managing customer-based valor da marca. Journal of Marketing, v. 57, p. 1-22, Jan. 1993.

KELLER, K. Strategic brand management: building, measuring, and managing brand equity. Upper Sadlle River-NJ: Prentice-Hall, 1998.

KUMAR, V. CLV: a path to higher profitability, working paper, University of Connecticut, Storrs, 2006.

KUMAR, V.; LEMON, K. N.; PARASURAMAN, A. Managing customers for value: an overview and research agenda. Journal of Service Research, v. 9, n. 2, p. 87-94, 2006.

KUMAR, V. Managing customers for frofit. Upper Saddle River: Pearson Education, 2008.

LEONE, R. P. et al. Linking brand equity to customer equity. Journal of Service Research, v. 9, n. 125, p. 125-138, Nov. 2006.

MALHOTRA, N. K. Pesquisa de marketing: uma orientação aplicada. 3. ed. Porto Alegre: Bookman, 2001.

MARKETING SCIENCE INSTITUTE. 2008-2010

Research Priorities: a guide to MSI Research Programs and Procedures. Disponível em: <http://www.msi.org/pdf/MSI_RP08-10.pdf>. Acesso em: 31 maio 2008.

NETO, A. Mensuração de brand equity baseada no consumidor: avaliação de escala multidimensional. 2003. 86f. Dissertação (Mestrado em Administração - ênfase em Marketing) - Programa de Pós Graduação em Administração - Escola de Administração Universidade Federal do Rio Grande do Sul, Porto Alegre, 2003.

OLIVEIRA, M. O. R. Valor da marca: conceitos, abordagens e o estado da arte no Brasil. In: ENCONTRO DE MARKETING DA ANPAD, 24. Curitiba. Anais... Curitiba: ANPAD, 2008. CDROM, p. 1-16.

OLIVER, R. L. Whence consumer loyalty? Journal of Marketing, v. 63, Special Issue, p. 33-44, 1999.
SHETH, J. N.; SISODIA, R. S. Feeling the heat - part I. Marketing Management, v. 4 n.2, p. 9-23, Fall 1995a.

SHETH, J. N.; SISODIA, R. S. Feeling the heatPart II. Marketing Management, v. 4, n.3, p.1933, Winter 1995b.

SRIVASTAVA, R. K.; SHERVANI, T. A.; FAHEY, L. Market-based assets and shareholder value: a framework for analysis. Journal of Marketing, v. 62, p. 2-18, Jan. 1998.

SRIVASTAVA, R. K.; SHERVANI, T. A.; FAHEY, L. Marketing, business processes and shareholder value: an organizationally embedded view of marketing activities and the discipline of marketing. Journal of Marketing, v. 63, p. 168179, 1999.

SRIVASTAVA, R. K.; SHOCKER, A. D. Brand equity: a perspective on its meaning and measurement. Technical Working Paper, report n. 91-124. Cambridge: Marketing Science Institute, 1991.

RAGGIO, R. D.; LEONE, R. P.. The theoretical separation of brand equity and brand value: managerial implications for strategic planning. Journal of Brand Management, v.14, p.380395, Mar. 2007.

RUST, R. T.; LEMON, K. N.; ZEITHAML, V. A. Return on marketing: using customer equity to focus marketing strategy. Journal of Marketing, v. 68, p. 109-127, Jan. 2004a.

RUST, R. T. et al. Measuring marketing productivity: current knowledge and future directions. Journal of Marketing, v.68, p.76-89, Oct. 2004b.

RUST, R. T.; ZEITHAML, V. A.; LEMON, K. N. Driving customer equity: how customer lifetime value is reshaping the corporate strategy. New York: The Free Press, 2000.

VARGO, S.; LUSCH, R. F. Evolving to a new dominant logic for marketing. Journal of Marketing, v. 68, p. 1-17, Jan. 2004.

VERHOEF, P. C.; LEEFSLANG, P. S. H. Getting marketing back to the boardroom: understanding the drivers of the marketing's Influence within 
the Firm. Working Papers Series, Issue 1, N 080001; MSI Reports, 2008.

VILLANUEVA, J.; HANSSENS, D. Customer equity: measurement, management and research opportunities. Foundations and Trends in Marketing, v. 1, n. 1, p. 1-95, 2007.
YOO, B.; DONTHU, N. Developing and validating a multidimensional consumerbased brand equity scale. Journal of Business Research, v.52, p. 1-14, 2001. 